\title{
Poly-arginine peptides reduce infarct volume in a permanent middle cerebral artery rat stroke model
}

\author{
Diego Milani ${ }^{2,3,4}$, Vince W. Clark ${ }^{1,2,3}$, Jane L. Cross ${ }^{1,2,3}$, Ryan S. Anderton ${ }^{3,4}$, Neville W. Knuckey 1,2,3 \\ and Bruno P. Meloni ${ }^{1,2,3^{*}}$
}

\begin{abstract}
Background: We recently reported that poly-arginine peptides have neuroprotective properties both in vitro and in vivo. In cultured cortical neurons exposed to glutamic acid excitotoxicity, we demonstrated that neuroprotective potency increases with polymer length plateauing at R15 to R18 ( $R=$ arginine resides). In an in vivo study in rats, we also demonstrated that R9D (R9 peptide synthesised with D-isoform amino acids) administered intravenously at a dose of $1000 \mathrm{nmol} / \mathrm{kg} 30 \mathrm{~min}$ after permanent middle cerebral artery occlusion (MCAO) reduces infarct volume. Based on these positive in vitro and in vivo findings, we decided to examine the neuroprotective efficacy of the L-isoform poly-arginine peptides, R12, R15 and R18 when administered at a dose of $1000 \mathrm{nmol} / \mathrm{kg} 30 \mathrm{~min}$ after permanent MCAO in the rat.
\end{abstract}

Results: At 24 h post-MCAO, there was reduced total infarct volume for R12 (12.8\% reduction) and R18 (20.5\% reduction), but this reduction only reached statistical significance for R18. Brain slice analysis revealed significantly reduced injury in coronal slices 4 and 5 for R18, and slice 5 for R12. The R15 peptide had no effect on infarct volume. Peptide treatment did not reveal any statistical significant improvement in functional outcomes.

Conclusion: While these findings confirm the in vivo neuroprotective properties of poly-arginine peptides, additional dose studies are required particularly in less severe transient MCAO models so as to further assess the potential of these agents as a stroke therapy.

Keywords: Poly-arginine peptides, Middle cerebral artery occlusion, Stroke, Neuroprotection

\section{Background}

Minimising brain injury following stroke is a critical clinical goal both to improve patient quality of life and to lessen the social and economic impacts of this devastating disorder. Currently, the most effective stroke therapy is to restore cerebral blood flow to a blocked artery using tPA and thrombectomy [1-3]. However, the current therapeutic window for coupled tPA \pm thrombectomy therapy is so narrow $(4.5 \mathrm{~h})$ that the majority of stroke patients are unable to receive the treatment. Moreover, for those that do, up to $7 \%$ develop intracranial haemorrhage as a

\footnotetext{
*Correspondence: bruno.meloni@wanri.uwa.edu.au

${ }^{3}$ Western Australian Neuroscience Research Institute, A Block, 4th Floor,

QEIl Medical Centre, Verdun St, Nedlands, WA 6009, Australia

Full list of author information is available at the end of the article
}

complication. In addition, tPA \pm thrombectomy is only available to patients having ready access to a hospital that has the facilities required for performing the procedures. Other treatments are only suitable for a small proportion of patients (e.g. hemicraniectomy to reduce intracranial pressure due to cerebral oedema) or provide only modest benefit (e.g. aspirin to reduce risk of clot propagation) [4]. As a consequence, while recent improvements in stroke therapy have been made, these have been limited and it is clear that there is urgent need for new, more widely applicable neuroprotective therapies that can be applied to stroke patients early by ambulance paramedics, in hospital emergency departments, and in remote locations away from tertiary hospitals. Additionally, any treatment that might improve the safety, therapeutic window 
and neuroprotective outcomes for tPA \pm thrombectomy would be of great clinical significance.

Against the backdrop of the limited nature of current therapies, we have recently demonstrated that poly-arginine (and arginine-rich) peptides have potent neuroprotective properties in in vitro injury models that mimic the effects of stroke [5-7]. We have also established that poly-arginine peptides, as well as other arginine-rich peptides, including TAT and penetratin belonging to a class of peptide with cell penetrating properties also possess intrinsic neuroprotective properties [5-7]. Moreover, our in vitro data show that neuroprotective potency is enhanced with increasing arginine content (e.g. polymer length) [6]. As evidence of their clinical applicability, we have demonstrated that the poly-arginine R9D significantly reduces infarct volume in vivo following permanent middle cerebral artery occlusion (MCAO) in the rat [6]. A recent report [8] has also demonstrated that poly-arginine 7 (R7) containing peptides are neuroprotective in an in vivo retinal ganglion NMDA excitotoxicity model.

The neuroprotective properties of poly-arginine peptides in vitro and in vivo suggest that they may have potential as a neuroprotective therapy for stroke patients. To further investigate the efficacy of poly-arginine peptides in vivo and given the positive results obtained with the R9D peptide, in this study we assess the neuroprotective efficacy of the longer L-isoform poly-arginine peptides R12, R15 and R18 when administered $30 \mathrm{~min}$ after permanent MCAO. In addition, unlike in our earlier R9D trial, this study assesses functional outcomes using three behavioural tests as well as infarct volume to gain an understanding of the functional consequences of neuroprotection.

\section{Results}

\section{Physiological and infarct volume measurements}

Physiological measurements before or during surgery confirmed the absence of any significant differences between animal treatment groups (Table 1). Data on the mean total infarct volumes and representative TTC stained coronal brain slices for each treatment group are presented in Fig. 1. These results show that the R18 peptide significantly reduced infarct volume $(20.5 \%$ reduction; $P=0.014)$. The R12 peptide also reduced infarct volume (12.8\% reduction), but not to a statistical significant extent $(P=0.105)$. By contrast, the R15 peptide had no effect on infarct volume. Rostral to caudal topographic analysis of infarcts in brain slices revealed that the R18 peptide significantly reduced brain injury in coronal slices $4(P=0.008)$ and $5(P=0.01)($ Fig. 2$)$. In addition, the R12 peptide significantly reduced brain injury in coronal slice $5(P=0.027)$.

There were three post-treatment animal deaths that occurred the day following surgery, one in the vehicle and two in the R12-treated animals. While the animal deaths could be directly related to stroke severity and/or treatment, the exact cause of the deaths could not be precisely determined on autopsy.

\section{Functional outcome assessment}

Neurological scores using the modified Bederson' scale for each treatment group are presented in Fig. 3. While neurological scores did not differ statistically between groups, the vehicle control group score was higher (1.9) than any of the scores for the peptide treatment groups $(<1.4)$, indicative of a possible positive treatment effect. Results for the rota-rod assessment for each treatment group are presented in Fig. 4. Results were highly variable within groups and no significant differences were detected.

For the adhesive tape removal test pre- and postMCAO measurements for time to detect tape, the number of attempts to remove tape and time taken to remove tape for each treatment group are presented in Fig. 5. As expected, the left paw was more adversely affected than the right paw, however there were no statistically significant differences between vehicle-treated versus peptide-treated groups. However, for the R12 peptide all parameters measured for the left paw, and two out of the three measurements obtained for the right paw showed a positive improvement, albeit not to a statistically significant extent.

Table 1 Physiological parameters for experimental animals used in study

\begin{tabular}{lcccc}
\hline & Saline $(\mathbf{N}=\mathbf{1 2})$ & $\mathbf{R 1 2}(\mathbf{N}=\mathbf{9})$ & $\mathbf{R 1 5}(\mathbf{N}=\mathbf{8})$ & $\mathbf{R} 18 \mathbf{( N = 8 )}$ \\
\hline $\mathrm{PaO}_{2}(\mathrm{mmHg})$ & $115.10 \pm 33.51$ & $124.30 \pm 18.40$ & $112.80 \pm 16.96$ & $120.60 \pm 20.34$ \\
$\mathrm{PaCO}_{2}(\mathrm{mmHg})$ & $42.92 \pm 5.82$ & $46.00 \pm 4.21$ & $39.38 \pm 5.20$ & $44.25 \pm 7.74$ \\
$\mathrm{pH}$ & $7.44 \pm 0.09$ & $7.33 \pm 0.08$ & $7.31 \pm 0.09$ & $7.42 \pm 0.08$ \\
Glucose $(\mathrm{mmol} / \mathrm{L})$ & $7.74 \pm 1.27$ & $7.42 \pm 1.06$ & $7.03 \pm 1.11$ & $7.13 \pm 1.08$ \\
Blood pressure $(\mathrm{mmHg})$ & $89.00 \pm 8.44$ & $78.44 \pm 6.98$ & $88.00 \pm 9.97$ & $79.63 \pm 12.65$ \\
Body temperature $\left({ }^{\circ} \mathrm{C}\right)$ & $37.48 \pm 0.18$ & $37.58 \pm 0.13$ & $37.46 \pm 0.21$ & $37.51 \pm 0.06$ \\
\hline
\end{tabular}

$\mathrm{PaO}_{2}, \mathrm{PaCO}_{2}, \mathrm{pH}$, blood pressure and glucose measured before MCAO. Body temperature data represent average over $2 \mathrm{~h}$ post-surgery monitoring period. Data are mean $\pm \mathrm{SD}$ 


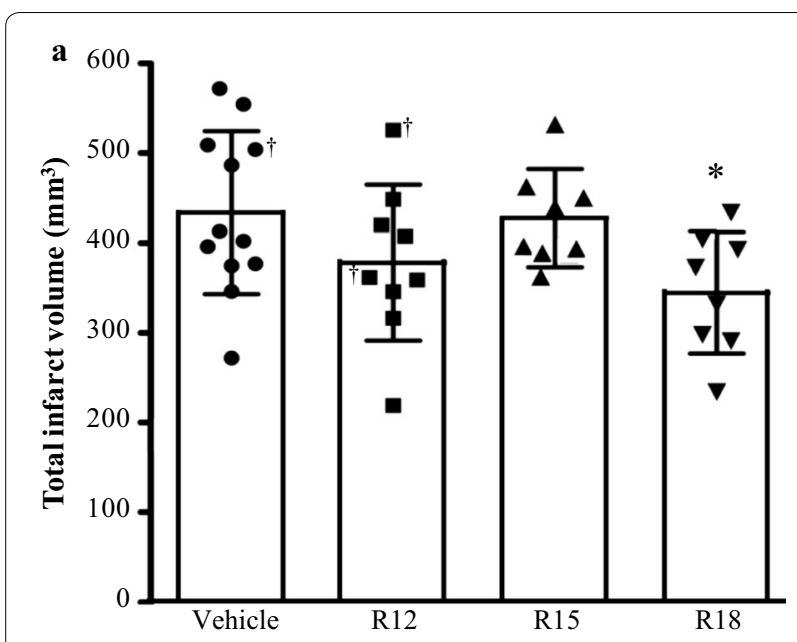

b

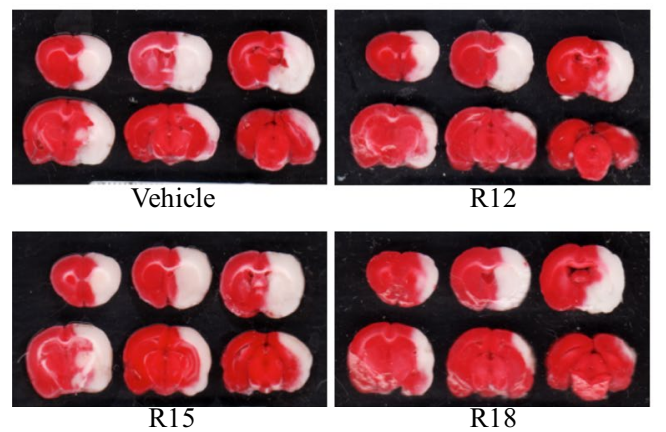

Fig. 1 Infarct volume measurements and coronal brain slices $24 \mathrm{~h}$ after permanent MCAO. Treatments were administered intravenously (saline vehicle or peptide $1000 \mathrm{nmol} / \mathrm{kg}$; in $600 \mu$ l volume over $6 \mathrm{~min}$ ) 30 min after MCAO. a Values are mean \pm SD. ${ }^{*} P<0.05$ when compared to the vehicle control group. ${ }^{\dagger} D e n o t e s$ animals that died the following day after surgery, before the $24 \mathrm{~h}$ post-MCAO end-point, but whose infarct volume was measured nonetheless. b Representative TTC coronal brain slices from vehicle and peptide treated animals

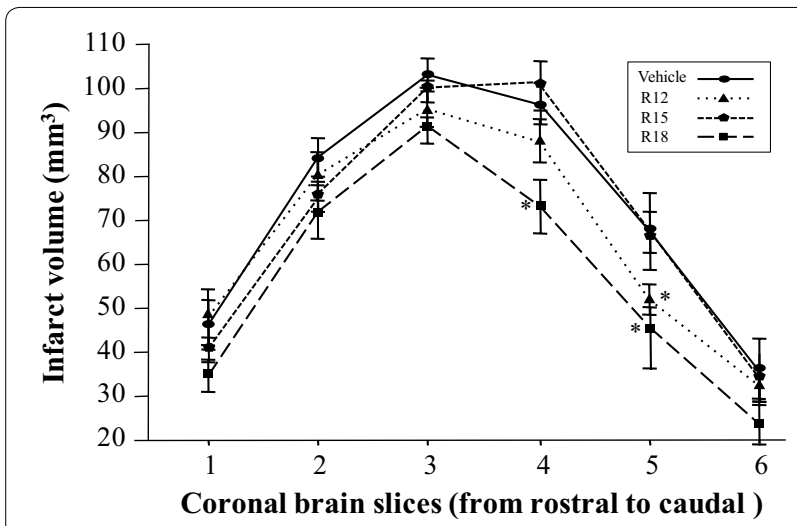

Fig. 2 Infarct volume analysis in coronal brain slices (1-6 from rostral to caudal). The R18 peptide significantly reduced injury in brain slices 4 and 5 , and the R12 peptide significantly reduced brain injury in slice 5. Values are mean $\pm S D ; * P<0.05$ when compared to the vehicle control group

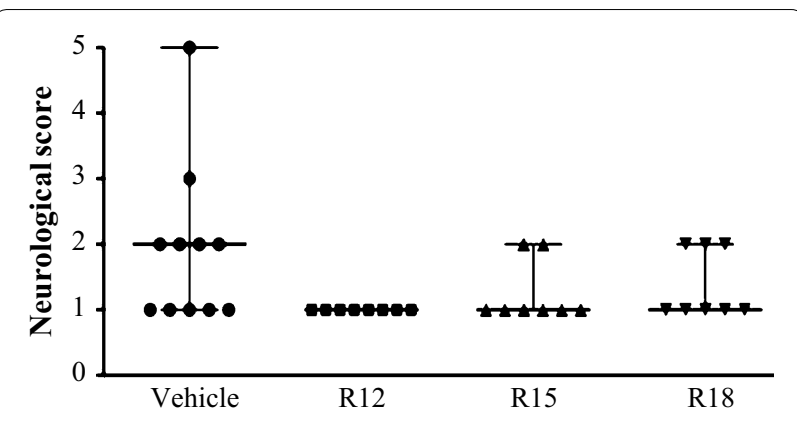

Fig. 3 Neurological grading scores $24 \mathrm{~h}$ after permanent MCAO $(0=$ no deficit, $4=$ major deficit) for saline (vehicle) and peptide (R12, R15, R18; $1000 \mathrm{nmol} / \mathrm{kg}$ ) treatment groups. Assessment was performed immediately before euthanasia. Lines on graph indicate range and median for neurological scores

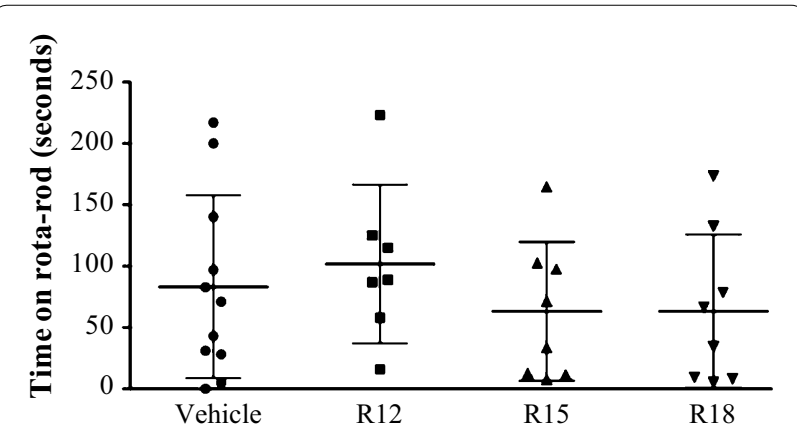

Fig. 4 Rota-rod performance $24 \mathrm{~h}$ after permanent MCAO for saline (vehicle) and peptide (R12, R15, R18; $1000 \mathrm{nmol} / \mathrm{kg}$ ) treatment groups. Results for this test were highly variable within groups and no significant differences were detected. Average time healthy presurgery animals remained on rota-rod was $78 \mathrm{~s}$ (data not shown). Values are mean $\pm S D$

\section{Weight loss measurement}

At experiment end, all treatment groups recorded a loss in weight, with the greatest weight loss occurring in the R15 peptide treatment group $(P=0.004$; Fig. 6$)$.

\section{Discussion}

In a previous study, we demonstrated that the poly-arginine peptide R9D could reduce infarct volume by $20 \%$ when administered intravenously $30 \mathrm{~min}$ post-MCAO [6], however no functional assessment was performed. The present study extends this previous study to include the poly-arginine peptides R12, R15 and R18 and explores their capacity to reduce infarct volume and improve functional outcomes when administered intravenously $30 \mathrm{~min}$ post-MCAO. Whereas R15 had no effect on infarct volume, R18 significantly reduced infarct volume $(20.5 \%$ reduction) and there was a trend towards reduced infarct volume with R12 (12.8 \% reduction). Importantly, all peptide treatments displayed a trend towards improvement 


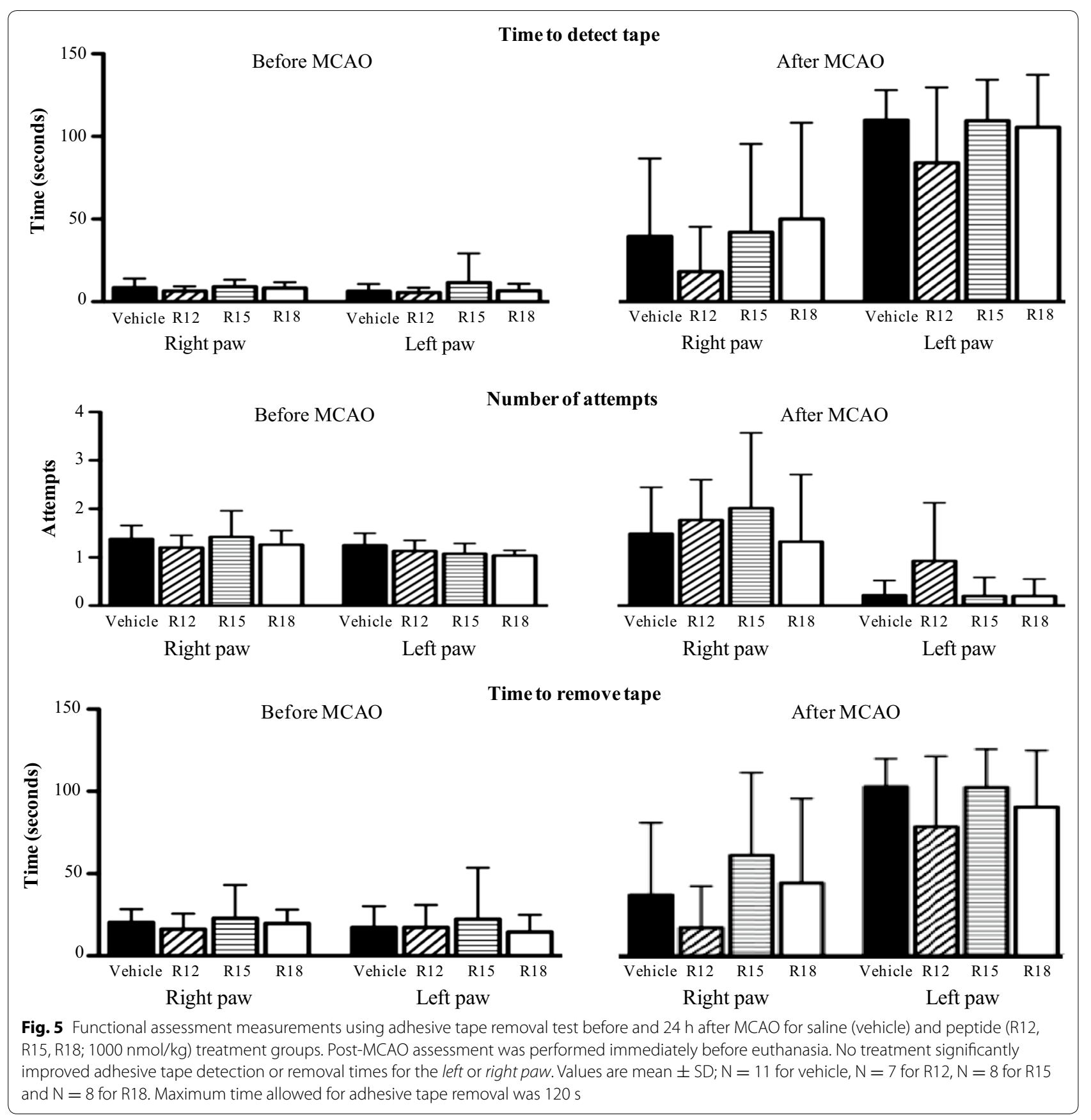

in one or more of the neurological functional tests. Whilst the level of infarct volume reduction was modest (12.8-20.5\%), this most likely reflects the severity of the stroke model used in this particular study where up to $90 \%$ of the affected brain hemisphere is infarcted by the stroke. It is also likely that the modest reductions in infarct volume, stroke severity and 24-h endpoint coupled with the small animal numbers used explain why the trend towards improvements in functional outcomes was not statistically significant. Despite the modest effects of the poly-arginine peptides following permanent MCAO, it is still possible that these peptides have potential clinical application, especially in less severe forms of stroke, stroke associated with cerebral reperfusion treatments (tPA \pm thrombectomy) and haemorrhagic stroke.

With respect to neuroprotective efficacy, further research is required to determine the optimal dose of the peptides to reduce infarct volume. It was particularly 


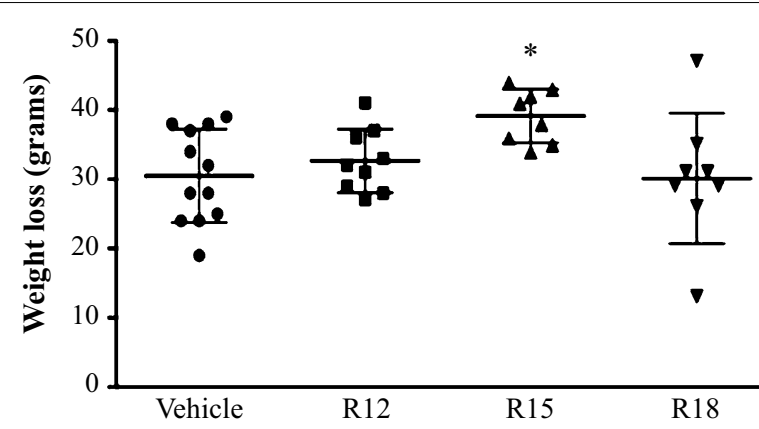

Fig. 6 Weight loss at $24 \mathrm{~h}$ after permanent MCAO for saline (vehicle) and peptide (R12, R15, R18; $1000 \mathrm{nmol} / \mathrm{kg})$ treatment groups. Values are mean $\pm \mathrm{SD} ;{ }^{*} P<0.05$ when compared to the vehicle control group

surprising that the R15 peptide did not have any affect on infarct volume reduction, despite showing comparable neuroprotective efficacy to R18 when assessed in an in vitro neuronal glutamate excitotoxicity model [6]. The reason why no observable neuroprotection was obtained for R15 is at present unknown, but it is possible that a higher or lower dose may be more effective than the dose used in the current study. Studies are currently underway in our laboratory to more definitively address questions surrounding effective dosage for a range of poly-arginine peptides in the in vivo stroke model.

The present study did not investigate the mechanism of action of peptides, but in previous studies we have shown that poly-arginine peptides have the capacity to reduce excitotoxic glutamic acid-induced calcium influx in cultured cortical neurons $[6,7]$. Based on this finding, as well as the findings of other studies, we have hypothesised that these peptides have the capacity to inhibit calcium influx by causing the internalisation of cell surface structures such as ion channels and thereby reduce the toxic neuronal calcium entry that occurs after excitotoxicity and cerebral ischemia. We have speculated that due to the cell penetrating properties of arginine-rich peptides, including putative "neuroprotective peptides" fused to the arginine-rich carrier peptide TAT, ion channel receptor internalisation occurs during neuronal endocytic uptake of the peptides [6,7]. Evidence that supports our hypothesis includes studies demonstrating that arginine-rich peptides: (1) interfere with the function of NMDA [9-14] and vanilloid receptors [15], voltage gated calcium channels [16-18] and the sodium calcium exchanger [13]; (2) cause internalisation or reduced surface expression of neuronal ion channels [11, 13, 18]; and (3) can induce the endocytic internalisation of epidermal growth factor receptor and tumour necrosis factor receptors in HeLa cells [19].
In support of the poly-arginine neuroprotective findings in the present study, a recent report [8] has confirmed the neuroprotective properties of poly-arginine 7 (R7) containing peptides and other arginine-rich peptides (TAT and TATNR2B9c) in an in vivo retinal ganglion NMDA excitotoxicity model. Moreover, the study also provides evidence for an additional neuroprotective mechanism associated with maintenance of mitochondrial function and integrity.

Studies in our laboratory to confirm peptide-induced internalisation of cell surface receptors and other neuroprotective mechanisms are in progress. While we have demonstrated that arginine-rich peptides have the capacity to reduce excitotoxic calcium influx, it will be important to obtain a more comprehensive understanding of peptide neuroprotective mechanism of action. Nevertheless our findings indicate poly-arginine peptides have both in vitro and in vivo neuroprotective properties and warrant further evaluation in different stroke models and other acute brain injury disorders.

\section{Conclusion}

The findings of this study further validates the neuroprotective properties of poly-arginine peptides [5-9], highlights their status a new class of neuroprotective agent and provides justification for their evaluation in different stroke models and other acute brain injury disorders. The findings also further question the mechanism of action of the many reported "neuroprotective peptides" fused to arginine-rich carrier peptides, which are thought to act through interaction with specific intracellular proteins, but which our data suggest may act through a common mechanism of action relating to peptide arginine content and positive charge.

\section{Methods \\ Peptides}

The R12 (H-RRRRRRRRRRRR-OH), R15 (H-RRRRRR RRRRRRRRR-OH) and R18 H-RRRRRRRRRRRRRR RRRR-OH) peptides used in the study were synthesised by China Peptides (Shanghai, China). The peptides were HPLC purified to $>94 \%$ purity. All peptides were prepared in $0.9 \%$ sodium chloride for injection (Pfizer, Perth, Australia) aliquoted into $650 \mu \mathrm{l}$ volumes in $3 \mathrm{ml}$ syringes and stored at $-20^{\circ} \mathrm{C}$ until use.

Rat permanent middle cerebral artery occlusion procedure This study was approved by the Animal Ethics Committee of the University of Western Australia and follows guidelines outlined by the Australian Code for the Care and use of Animals for Scientific Purposes. The experimental procedure for performing the permanent middle cerebral artery occlusion (MCAO) stroke model 
has been described previously [20, 21]. Briefly, male Sprague-Dawley rats weighing 270-320 g were kept under controlled housing conditions with a $12 \mathrm{~h}$ lightdark cycle and with free access to food and water. Experimental animals were fasted overnight and subjected to filament permanent MCAO. In order to monitor blood pressure and withdraw blood samples, a cannula was inserted in the tail artery. Between 50 and $200 \mu \mathrm{L}$ of blood was used for glucose (glucometer; MediSense Products, Abbott Laboratories, Bedford, MA, USA) and other measurements $\left(\mathrm{PaO}_{2}, \mathrm{PaCO}_{2}, \mathrm{pH}\right.$; ABL5, Radiometer, Copenhagen, Denmark). The MCAO procedure was considered successful based on a $>25 \%$ decrease from baseline in cerebral blood flow (CBF) after insertion of filament, as measured by laser Doppler flowmetry. During surgery temperature was closely monitored using a rectal probe (Physitemp Instruments, Clifton, USA) and maintained at $37.5 \pm 0.5^{\circ} \mathrm{C}$, with fan heating or cooling.

Thirty minutes post-MCAO, rats were intravenously treated with the peptide $(1000 \mathrm{nmol} / \mathrm{kg}$ in $600 \mu \mathrm{L}$ over $6 \mathrm{~min})$ or vehicle $(0.9 \%$ sodium chloride for injection; $600 \mu \mathrm{L}$ over $6 \mathrm{~min}$ ). Treatments were administered via the right internal jugular vein and infusion pump. Treatments were randomised and all procedures were performed blinded to treatment.

Twenty-fours hours post-MCAO, infarct area assessment was performed by preparing $2 \mathrm{~mm}$ thick cerebral coronal brain slices, and incubating in $3 \% 2,3,5$ triphenyltetrazolium chloride (TTC; Sigma-Aldrich, St. Louis, USA) at $37{ }^{\circ} \mathrm{C}$ for $20 \mathrm{~min}$, followed by fixation in $4 \%$ formalin at room temperature overnight. Digital images of coronal sections were acquired using a colour scanner and analysed by an operator blind to treatment status, using ImageJ software (3rd edition, NIH, Bethesda, USA). The total infarct volume was determined by measuring the areas of infarcted tissue on both sides of the $2 \mathrm{~mm}$ sections. These measured areas were corrected for cerebral oedema by multiplying the infarct volume for the oedema index (calculated by dividing the total volume of the stroke-affected hemisphere by the total volume of the contralateral hemisphere) [22].

A total of 42 animals were used in the trial. Five animals were excluded from the study; two animals were euthanased due to subarachnoid haemorrhage, one animal was excluded due to insufficient decrease in CBF, one animal was excluded due to pyrexia, and one died during surgical recovery for an unknown reason.

\section{Post-surgical monitoring}

Following surgery animals were placed in a clean cage with free access to food and water. The body temperature of animals was measured every $30-60$ min using a rectal probe for at least $2 \mathrm{~h}$ post-surgery, and maintained between 37.0 and $37.8^{\circ} \mathrm{C}$. To avoid hypothermia, rat cages were placed on a heating mat during the post-surgical monitoring and housed in a holding room maintained at $26-28{ }^{\circ} \mathrm{C}$. If necessary, additional heating or cooling was performed by applying fan heating or cold water spray.

\section{Behavioural testing}

To determine if peptide treatment was associated with improved sensorimotor outcomes, three neurological tests were performed $24 \mathrm{~h}$ post-stroke.

\section{Neurological assessment test}

The scoring system was performed using the modified Bederson' scale. Scores range from 0 for no deficits, 1 for flexed forepaw, 2 for inability to resist lateral push, 3 for circling, 4 for agitated circling and 5 for unresponsive to stimulation/stupor [23].

\section{Adhesive tape removal test}

This is a bilateral asymmetry paw-test, which assesses sensorimotor impairment [24]. Adhesive tape (Diversified Biotech, Dedham, USA) $10 \mathrm{~mm} \times 10 \mathrm{~mm}$ in size was placed on the palmar surface of the forepaw and the time taken for the first attempt to remove tape, the number of attempts to remove tape and the total time taken to remove tape recorded. Each forelimb was assessed sequentially starting with the unaffected side (right side) with animals having a maximum of $120 \mathrm{~s}$ to complete the task (normal rats usually take between 5 and 30 $s$ to remove the tape). Animals were tested a total of six times, three times on the day before surgery and three times $24 \mathrm{~h}$ post-MCAO. Mean values were calculated for each forepaw for the pre- and post-surgery trials.

\section{Rota-rod test}

This test assesses balance and coordination by assessing a rat's ability to remain walking on a rotating rod when its speed of rotation gradually increases from 4 to 40 revolutions per minute. The time at which the animal falls is recorded. Typically rats fall $27-137 \mathrm{~s}$ after placement on the rod.

\section{Statistical analysis}

Mean infarct volume measurements (total and coronal slices) for each treatment group was compared to the vehicle control group by analysis of variance (ANOVA) followed by the Fisher's post hoc analysis. Data from neurological assessment were analysed using Kruskal-Wallis test [25]. Data from adhesive tape and rota-rod tests were analysed using ANOVA followed by post hoc analysis using Scheffe's multiple comparison procedure. A value 
of $P<0.05$ was considered significant for all data sets. Data in figures are presented as mean \pm standard deviation (SD).

\section{Authors' contributions}

DM, VC and JC contributed to animal procedures, post-surgical monitoring, functional assessment, infarct volume analysis or statistical analysis. BM, DM, NK and RA contributed to experimental design and manuscript preparation. All authors read and approved the final manuscript.

\section{Author details}

${ }^{1}$ Centre for Neuromuscular and Neurological Disorders, The University of Western Australia, Nedlands, Australia. ${ }^{2}$ Department of Neurosurgery, Sir Charles Gairdner Hospital, QEll Medical Centre, Nedlands, WA, Australia. ${ }^{3}$ Western Australian Neuroscience Research Institute, A Block, 4th Floor, QEll Medical Centre, Verdun St, Nedlands, WA 6009, Australia. ${ }^{4}$ School of Heath Sciences, The University of Notre Dame Australia, Fremantle, WA, Australia.

\section{Acknowledgements}

This study has been supported by the University of Notre Dame Australia, the Western Australian Neuroscience Research Institute (WANRI), the Department of Neurosurgery, Sir Charles Gairdner Hospital and by a Neurotrauma Research Program of Western Australia research grant. We also thank Prof Norman Palmer for providing assistance in the preparation of the manuscript.

\section{Competing interests}

B. P. Meloni and N. W. Knuckey are the holders of several patents regarding the use of arginine-rich peptides as neuroprotective treatments. The other authors declare no competing interests.

\section{Compliance with ethics requirements}

This study was approved by the Animal Ethics Committee of the University of Western Australia and follows guidelines outlined by the Australian Code for the Care and use of Animals for Scientific Purposes and National Health and Medical Research Council of Australia.

Received: 9 January 2016 Accepted: 27 April 2016

Published online: 03 May 2016

\section{References}

1. Campbell BC, Mitchell PJ, Kleinig TJ, Dewey HM, Churilov L, Yassi N, Yan B, Dowling RJ, Parsons MW, Oxley TJ, Wu TY, Brooks M, Simpson MA, Miteff F, Levi CR, Krause M, Harrington TJ, Faulder KC, Steinfort BS, Priglinger M, Ang T, Scroop R, Barber PA, McGuinness B, Wijeratne T, Phan TG, Chong W, Chandra RV, Bladin CF, Badve M, Rice H, de Villiers L, Ma H, Desmond PM, Donnan GA, Davis SM, EXTEND-IA Investigators. Endovascular therapy for ischemic stroke with perfusion-imaging selection. N Engl J Med. 2015;372:1009-18.

2. Goyal M, Demchuk AM, Menon BK, Eesa M, Rempel JL, Thornton J, Roy D, Jovin TG, Willinsky RA, Sapkota BL, Dowlatshahi D, Frei DF, Kamal NR, Montanera WJ, Poppe AY, Ryckborst KJ, Silver FL, Shuaib A, Tampieri D, Williams D, Bang OY, Baxter BW, Burns PA, Choe H, Heo JH, Holmstedt CA, Jankowitz B, Kelly M, Linares G, Mandzia JL, Shankar J, Sohn SI, Swartz RH, Barber PA, Coutts SB, Smith EE, Morrish WF, Weill A, Subramaniam S, Mitha AP, Wong JH, Lowerison MW, Sajobi TT, Hill MD, ESCAPE Trial Investigators. Randomized assessment of rapid endovascular treatment of ischemic stroke. N Engl J Med. 2015;372:1019-30.

3. Jovin TG, Chamorro A, Cobo E, de Miquel MA, Molina CA, Rovira A, San Román L, Serena J, Abilleira S, Ribó M, Millán M, Urra X, Cardona P, LópezCancio E, Tomasello A, Castaño C, Blasco J, Aja L, Dorado L, Quesada H, Rubiera M, Hernandez-Pérez M, Goyal M, Demchuk AM, von Kummer R, Gallofré M, Dávalos A, REVASCAT Trial Investigators. Thrombectomy within 8 hours after symptom onset in ischemic stroke. N Engl J Med. 2015;372:2296-306

4. Donnan GA, Fisher M, Macleod M, Davis SM. Stroke Lancet. 2008:371:1612-23.
5. Meloni BP, Craig AJ, Milech N, Hopkins RM, Watt PM, Knuckey NW. The neuroprotective efficacy of cell-penetrating peptides TAT, penetratin, Arg-9, and Pep-1 in glutamic acid, kainic acid, and in vitro ischemia injury models using primary cortical neuronal cultures. Cell Mol Neurobiol. 2014;34:173-81.

6. Meloni BP, Brookes LM, Clark VW, Cross JL, Edwards AB, Anderton RS, Hopkins RM, Hoffmann K, Knuckey NW. Poly-arginine and arginine-rich peptides are neuroprotective in stroke models. J Cereb Blood Flow Metab. 2015;35:993-1004

7. Meloni BP, Cross JL, Edwards AB, Anderton RS, O'Hare Doig RL, Fitzgerald $M$, Palmer TN, Knuckey NW. Neuroprotective peptides fused to argininerich cell penetrating peptides: neuroprotective mechanism likely mediated by peptide endocytic properties. Pharmacol Ther. 2015;153:36-54.

8. Marshall J, Wong KY, Rupasinghe CN, Tiwari R, Zhao X, Berberoglu ED, Sinkler C, Liu J, Lee I, Parang K, Spaller MR, Hüttemann M, Goebel DJ. Inhibition of N-methyl-D-aspartate-induced retinal neuronal death by polyarginine peptides is linked to the attenuation of stress-induced hyperpolarization of the inner mitochondrial membrane potential. J Biol Chem. 2015;290:22030-48.

9. Ferrer-Montiel AV, Merino JM, Blondelle SE, Perez-Payà E, Houghten RA, Montal M. Selected peptides targeted to the NMDA receptor channel protect neurons from excitotoxic death. Nat Biotechnol. 1998;16:286-91.

10. Tu W, Xu X, Peng L, Zhong X, Zhang W, Soundarapandian MM, Balel C, Wang M, Jia N, Zhang W, Lew F, Chan SL, Chen Y, Lu Y. DAPK1 interaction with NMDA receptor NR2B subunits mediates brain damage in stroke. Cell. 2010;140:222-34.

11. Sinai L, Duffy S, Roder JC. Src inhibition reduces NR2B surface expression and synaptic plasticity in the amygdala. Learn Mem. 2010;17:364-71.

12. Brittain JM, Chen L, Wilson SM, Brustovetsky T, Gao X, Ashpole NM, Molosh Al, You H, Hudmon A, Shekhar A, White FA, Zamponi GW, Brustovetsky N, Chen J, Khanna R. Neuroprotection against traumatic brain injury by a peptide derived from the collapsin response mediator protein 2 (CRMP2). J Biol Chem. 2011;286:37778-92.

13. Brustovetsky T, Pellman JJ, Yang XF, Khanna R, Brustovetsky N. Collapsin response mediator protein 2 (CRMP2) interacts with $\mathrm{N}$-methyl-Daspartate (NMDA) receptor and $\mathrm{Na}^{+} / \mathrm{Ca}^{2+}$ exchanger and regulates their functional activity. J Biol Chem. 2014;289:7470-82.

14. Fan J, Cowan CM, Zhang LY, Hayden MR, Raymond LA. Interaction of postsynaptic density protein-95 with NMDA receptors influences excitotoxicity in the yeast artificial chromosome mouse model of Huntington's disease. J Neurosci. 2009;29:10928-38.

15. Planells-Cases R, Aracil A, Merino JM, Gallar J, Pérez-Payá E, Belmonte C, González-Ros JM, Ferrer-Montiel AV. Arginine-rich peptides are blockers of VR-1 channels with analgesic activity. FEBS Lett. 2000;481:131-6.

16. Brittain JM, Duarte DB, Wilson SM, Zhu W, Ballard C, Johnson PL, Liu N, Xiong W, Ripsch MS, Wang Y, Fehrenbacher JC, Fitz SD, Khanna M, Park CK, Schmutzler BS, Cheon BM, Due MR, Brustovetsky T, Ashpole NM, Hudmon A, Meroueh SO, Hingtgen CM, Brustovetsky N, Ji RR, Hurley JH, Jin X, Shekhar A, Xu XM, Oxford GS, Vasko MR, White FA, Khanna R. Suppression of inflammatory and neuropathic pain by uncoupling CRMP-2 from the presynaptic $\mathrm{Ca}^{2+}$ channel complex. Nat Med. 2011;17:822-9.

17. Garcia-Caballero A, Gadotti VM, Stemkowski P, Weiss N, Souza IA, Hodgkinson V, Bladen C, Chen L, Hamid J, Pizzoccaro A, Deage M, François A, Bourinet E, Zamponi GW. The deubiquitinating enzyme USP5 modulates neuropathic and inflammatory pain by enhancing CaV32 channel activity. Neuron. 2014;83:1144-58.

18. Feldan P, Khanna R. Challenging the cathechism of therapeutics for chronic neuropathic pain: targeting CaV22 interactions with CRMP2 peptides. Neurosci Lett. 2013;557:27-36.

19. Fotin-Mleczek M, Welte $S$, Mader O, Duchardt F, Fischer R, Hufnagel H, Scheurich P, Brock R. Cationic cell-penetrating peptides interfere with TNF signalling by induction of TNF receptor internalization. J Cell Sci. 2005;118:3339-51.

20. Campbell K, Meloni BP, Knuckey NW. Combined magnesium and mild hypothermia $\left(35^{\circ} \mathrm{C}\right)$ treatment reduces infarct volumes after permanent middle cerebral artery occlusion in the rat at 2 and 4 , but not $6 \mathrm{~h}$. Brain Res. 2008;1230:258-64.

21. Liu S, Zhen G, Meloni BP, Campbell K, Winn HR. Rodent stroke model guidelines for preclinical stroke trials (1st edition). J Exp Stroke Transl Med. 2009:2:2-27. 
22. Campbell K, Meloni BP, Zhu H, Knuckey NW. Magnesium treatment and spontaneous mild hypothermia after transient focal cerebral ischemia in the rat. Brain Res Bull. 2008;77:320-2.

23. Bederson JB, Pitts LH, Tsuji M, Nishimura MC, Davis RL, Bartkowski H. Rat middle cerebral artery occlusion: evaluation of the model and development of a neurologic examination. Stroke. 1986;17:472-6.

24. Komotar RJ, Kim GH, Sughrue ME, Otten ML, Rynkowski MA, Kellner CP, Hahn DK, Merkow MB, Garrett MC, Starke RM, Connolly ES. Neurologic assessment of somatosensory dysfunction following an experimental rodent model of cerebral ischemia. Nat Protoc. 2007;2:2345-7.

25. Rogers DC, Campbell CA, Stretton JL, Mackay KB. Correlation between motor impairment and infarct volume after permanent and transient middle cerebral artery occlusion in the rat. Stroke. 1997;28:2060-5.

\section{Submit your next manuscript to BioMed Central and we will help you at every step:}

- We accept pre-submission inquiries

- Our selector tool helps you to find the most relevant journal

- We provide round the clock customer support

- Convenient online submission

- Thorough peer review

- Inclusion in PubMed and all major indexing services

- Maximum visibility for your research

Submit your manuscript at

www.biomedcentral com/submit 